\title{
Chinese and American Cultural Differences Reflected by Their Totems: Chinese Dragon and American Eagle
}

\author{
Huan Yan, Xuanlin Chen, Wanyu Chen \\ College of International Education, Zunyi Medical University, Zunyi, China \\ Email:465090628@qq.com,978649387@qq.com,578181346@qq.com
}

How to cite this paper: Yan, H., Chen, X. L., \& Chen, W. Y. (2018). Chinese and American Cultural Differences Reflected by Their Totems: Chinese Dragon and American Eagle. Creative Education, 9, 1945-1956. https://doi.org/10.4236/ce.2018.913142

Received: September 26, 2018

Accepted: October 15, 2018

Published: October 18, 2018

Copyright (c) 2018 by authors and Scientific Research Publishing Inc. This work is licensed under the Creative Commons Attribution International License (CC BY 4.0).

http://creativecommons.org/licenses/by/4.0/

\section{(c) (i) Open Access}

\begin{abstract}
Totem, as the national symbol, reflects a nation's culture, spirit and traditional values. This paper, basing on a lot of reading on Sino-US cultural differences, will explore the Sino-US cultural differences from a totally new way, the different characteristics of the totems of the two countries-the Chinese dragon and the American Eagle, and the different values, ways of thinking and cultural traditions shown by their totems respectively. This paper not only reveals the cultural differences between the two countries, more importantly, from the outside phenomenon to the inside nature, it finds out the underlying causes of these differences through comparative analysis. Hoping to enhance the mutual understanding between the two peoples and show the world that the Chinese people has always been a peace-loving nation since ancient time under the current situation that the Western countries strongly play up the theory of "China threat".
\end{abstract}

\section{Keywords}

Cultural Differences, Totem, Chinese Dragon, American Eagle

\section{Introduction}

China, one of the four ancient civilizations and the greatest developing country in the world, represents the typical Oriental Culture. United States, as one of the youngest countries in the world, but also the world's most developed countries, is the representative of the Western capitalist countries. No doubt that the two great countries occupy a pivotal position in the political, economic and cultural process of human history. However, with different historical and geographical factors, the two countries surely have many differences in culture. These differ- 
ences are complex and multifaceted. They have brought a lot of obstacles and gaps to the communication and understanding between the people of these two countries. In today's tide of globalization, with various civilizations colliding with each other, an increasing number of ethnic conflicts occur, especially the conflicts between Eastern and Western cultures. There is huge difference between Eastern and Western countries, which is very harmful to the globalization, peace and unity of the world.

"Totem, as a national symbol, reflects the nation's culture, spirit and traditional values." (Zhang \& Zhang, 2008) This paper will explore the Sino-US cultural differences from the different characteristics of the two countries' totems-the Chinese dragon and the American eagle, and the reason why these two animals have been chosen as symbols of the two nations, hoping to help people have a better understanding of the cultural differences between the two countries and the reasons for its formation, and to enhance the mutual understanding between the two peoples so that they can better understand each other.

\section{Comparison of Cultural Connotations of Chinese Dragon and American Eagle}

\subsection{The Status of Dragon in China and Eagle in America}

In the year of 1872, the eagle was affirmed as the national bird by the American council, and since then it has become the symbol of the United States. Eagle logo is not only printed in the United States national emblem, but also very common in American people's daily life. The "Eagle" is considered as the nation's totem by Americans.

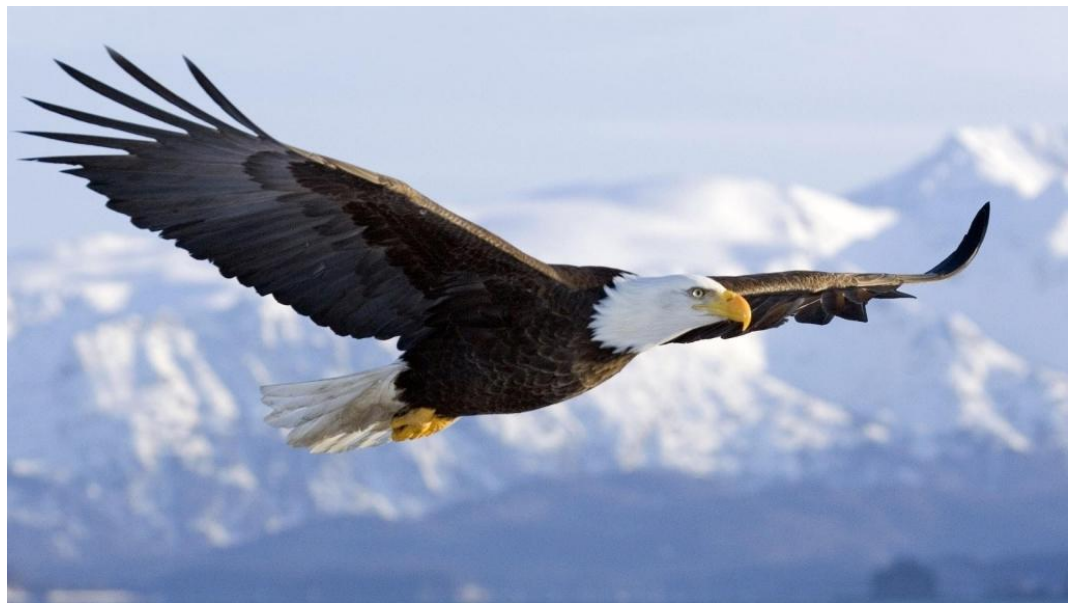

Chinese dragon originated in the early Neolithic. "After eight thousand years of development, evolution and sublimation, it has been widely accepted by both people in mainland and overseas as the totem of spiritual symbol, cultural icon as well as emotional ties of the nation." (Zeng, 2001) The Chinese dragon is full of mythology, and is highly respected and worshipped by the whole nation. The Chinese people are very proud of being the descendants of the Dragon. 


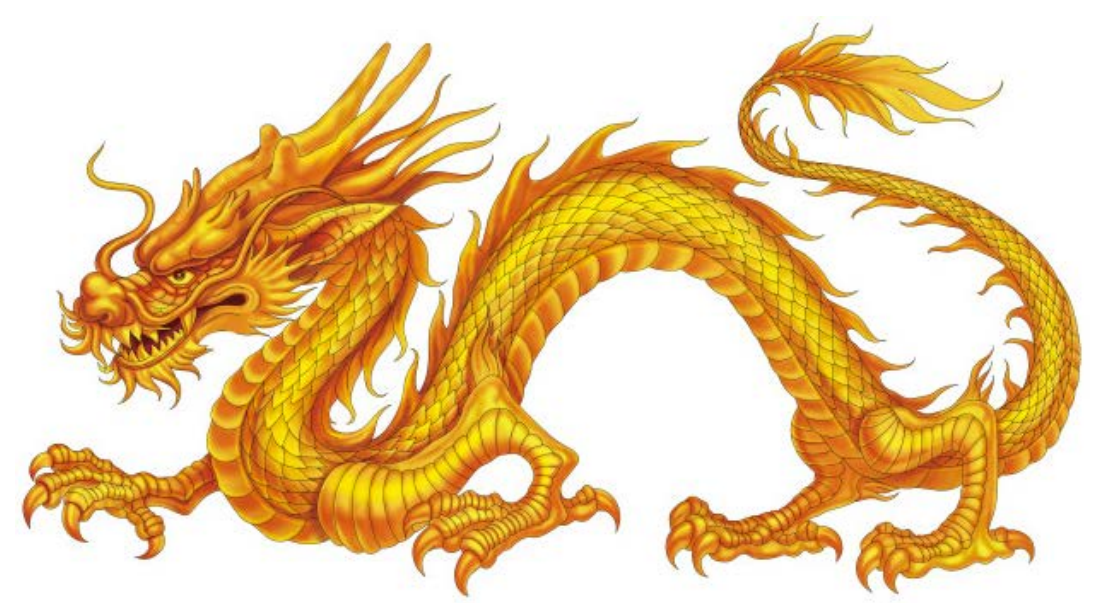

\subsection{Comparison of Cultural Connotations of Dragon and Eagle}

By analyzing the characteristics of the two animals-Chinese dragon and American eagle, we have found many differences between them. This paper will discuss these differences from the following three aspects.

\subsubsection{Self-Superiority Complex vs. Suffering Consciousness}

The Chinese dragon has been superior to other things since the time it comes into being. Many scholars believe that Chinese dragon is a supernatural thing imagined by ancient Chinese, just as what is written in the book Do Anything They Want in Eight Thousand Years "The Chinese dragon is a kind of integrated Divinity made by integrating many animals such as fish, crocodiles, snakes, horses and so on, with natural celestial phenomena such as clouds, lightning, rainbow etc." (Su, 1982) The most prominent characteristic of the Chinese dragon is that it is above all the life-form and is the envoy that can connect the Heaven with the Earth. It is also the messenger that can fly onto the sky as well as dive into the sea and transmits information between Man and God. Endowed with so much supernatural power, the dragon is immortal and need not worry about the threats from other creatures, for others are just mortals. Being inborn with such a high status as well as apotheosized power, the dragon has long been highly respected and worshiped by Chinese people, thus it enjoys an innate superiority complex.

Even though the eagle is known as the king of the sky, it is not easy for it to become the ruler of the sky. It must go through a great deal of inhuman sufferings. It is fair to say that the growth of an eagle is a process full of excepted difficulties. First of all, when the time an eagle, together with its brothers and sisters, was born, their parents will make them fight against each other and only the winner will survive, while the losers will die. The eagle has learned the cruelty of life since the very beginning of its life. The winner eagle, then, will learn to fly from its parents. The process of learning flying is also very cruel. The young eagle will be forced by its parents to fall down from the nest again and again, when it is about to fall to the bottom, and almost fall into pieces, the potentiality of the young eagle will play out. Finally, through such a heartless and ruthless 
training, the young eagle learns to fly. However, that is not the end of the ordeal. After knowing how to fly and with the basic ability to survive, the young eagle will be expelled from the house, and obliged to live independently. "Brought up in this way the eagle will always carry with it a sense of suffering Consciousness throughout its life, for it has understood the truth since the very beginning of its life that 'if you are not strong enough, then your life will become in danger"'. (Ren, 2010) So an eagle has to worry about its life all the time and keep practicing its skills to make itself strong enough to fight against any adversaries.

\subsubsection{Collectivism vs. Individualism}

The Chinese dragon is a kind of integrated Divinity which is made up of different parts of various animals' bodies. It shows vividly the soul of Chinese culture-introjection and harmony. The dragon itself is a product of introjection which attaches much importance to the harmony of the whole body. The harmonious appearance of dragon symbolizes the harmony of the collective which highlights the appropriate adjustment and compromise in the interpersonal communication. It emphasizes that the collective always comes first when its interests collide with personal interests, and advocate the self-sacrifice for the collective.

However, just as what is written in 2.2.1, being brought up in such a heartless and ruthless manner, the eagle has to fight to its utmost to maintain its life. It is well known that eagle is a kind of bird with the longest life expectancy in the world. It can live as long as 70 years. However, few people know that each day of the 70 years is not easy for an eagle, for it has to struggle for living so long. First, a young eagle has to fight against its brothers or sisters to win the chance for living. Then, it will work hard to meet the cruel life challenge. The hardship of the training is beyond one's imagination. When an eagle comes to its 40 s, its claws begin to age and cannot grasp the prey, its beak becomes long and curved and its wings become increasingly heavy which makes it very difficult to fly. There are only two choices at this time: waiting for death or re-engineering for regeneration. The eagle choosing the latter one will go through a painful process of updating. It first has to fly to the peak of a mountain, nest against the cliff and spend a long and painful 150 days there. During this time, it has to hit the rocks heavily with its long-curved beak, until it is completely off, and then wait for a new beak to grow out. After the new beak grows out, the eagle will use it to pull out its nails one by one. And when new nails grow out, the eagle must pull out its feathers piece by piece with its new nails. After the new feathers grow out, it can fly freely in the vast sky again and continue to live the left 30 years' life journey. It is fair to say that the life of an eagle is a life filled with live-or-die tests, by conquering the evil of death for many times, the eagle has a special understanding of the value of life. Thus, it values its life as the most important thing, whoever threats its life or its status will be attacked heavily by it. From the above analysis, it is not difficult for us to make a conclusion that forced by life, the eagle becomes very perseverant and egotistical, it will sacrifice anything, even 
itself, for its better life. So, individualism and perseverance are significant characteristics of the eagle.

\subsubsection{Romanticism vs. Realism}

"The dragon is not a real animal. It does not exist in the real world. It is a fictitious animal with supernatural powers which is the crystal of the ancient Chinese romantic imaginations." (Wang, 2007) Dragon has been endowed with a lot of blissful sense since it comes into being. It is an immortal Divinity which carries enormous hope of the Chinese nation. In the ancient time, the dragon bears three main responsibilities. The first one is the messenger that can fly onto the sky as well as dive into the sea and transmit information between Man and God. It symbolizes the emperor and divinity. Since ancient times, the emperor of China is regarded as the embodiment of dragon, and is sent by the Heaven to dominate the earth, which is full of romantic magic. Second, the dragon controls the raining. Since China is an ancient agricultural country, its agriculture has been constrained by the floods or droughts. The growth of crops depends highly on the amount of rain, likewise, the outcome of the harvest has a direct impact on people's life. The ancient Chinese respect and worship the Heaven, thus dragon is apotheosized as the Divinity sent by the Heaven to charge the rain. Every year, the emperor of China will assemble his people to beg the dragon for a better weather. Third, dragon is an auspicious and mysterious sign which implies the blessing of the Heaven. It is said that when the world is peaceful, harmonious and prosperous, the dragon will appear in the sky to show the good fortune. The legendary "Five Emperors" in the antediluvian period-the Emperor Huang, Zhuan $\mathrm{Xu}$, Di Ku, Tang Yao and Yu Shun all have links with dragon. Where there is a dragon, there is an auspicious sign. Dragon carries the sound romantic feelings of the Chinese people. Thus, the legend of it is full of romantic imaginations.

The eagle does exist in the real world and can be seen or even touched by we human beings. And no matter how powerful it is, an eagle is still mortal. It will experience sickness and death as well. An eagle suffers a lot throughout its life, and it is these sufferings that enable it to become the king of the sky. The drastic competition for survive drives the eagle to become increasingly realistic as it grows, and it has learned that there is no one who can be depended on except itself since it was very young. Forced by life, the young eagles have to fight against each other to win the chance for living. Then the winner will be forced by its parents to fall down from the nest again and again to learn flying. After knowing basic surviving skills, the eagle will be expelled out of the house and to meet the challenges of life independently. It is acknowledged that the life of an eagle is a history of struggle. An eagle, through the baptism of various trials and tribulations, has huge courage, strength and the mettle to be an emperor. The government of the United States calls on its citizens to learn the fighting spirit, perseverance, determination and confidence of the eagle, as well as its courage and power to overcome all difficulties. All in all, the life of an eagle is successful and 
brilliant, meanwhile, it is also full of anguishes and afflictions. There is an old Chinese saying that "one will feel colder when he stands higher". The eagle, flying high in the sky, suffers a lot of ups and downs of life. Thus, it has seen and experienced the reality of life. From what has been written above, we can safely conclude that the life of an eagle is an example of realism.

\section{Reasons of Chinese and American Cultural Differences}

With different historical and geographical factors, there surely are many political, economic and cultural differences between China and the United states. In the following part, we will discuss the specific reasons that cause the cultural differences in details.

\subsection{A Traditional Country vs. a Young Country}

\subsubsection{China-A Traditional Country}

The Chinese nation has a history of more than five thousand years, and it is known as one of the four ancient civilizations. With such a splendid civilization and prosperous culture, the Chinese has been carrying a sense of self-superiority since old times. The ancient Chinese call the place where they live "Zhongyuan", which means "the Central Plain" in English. They always take it for granted that the great China has a vast land with abundant resources and is the most prosperous and civilized place in the world, while the lands outside the Central Plain are barbaric, i.e. the land of uncivilized barbarians. "The relatively superior geographical environment has gestated the Chinese self-sufficient farming culture, and our ancestors need not earn their living through expansion." (Hofstede, 2001) They are very satisfied with their subsistent life style and feel rather safe. "This sense of security and self-satisfaction cannot be matched by any other nations. With such a full sense of security and self-satisfaction, the Chinese nation has gradually formed a kind of family and plowland respect as well as harmony-oriented cultural feelings." (Gudykunst \& Kim, 1997) Historically, attracted by the splendid civilization and material wealth, the minorities living outside Zhongyuan have repeatedly invaded it. However, the central government just resists the attack to keep the minorities outside the central plain. It seldom counter-attacks them actively, not to say initiates a battle. "With the sense of psychological and cultural superiority, the heavenly kingdom considers itself superior to other countries, and does not have any ambition to conquer the surrounding 'barbarian lands'." (Song, 2007) 1000 years ago, Matteo Ricci, from the view of a European, concluded that "the Chinese are very contented with their life, and have no expedition attempt."

Chinese culture has always cherished the ambition to save the world, the four steps of a perfect life written in The Great Learing and The Book of Rites "self-cultivating; family-regulating; state-ordering; then the great land-governing" has been pursued by generations and generations of the Chinese nation. "If one lives a life of hardships, he must try to manage himself alone, but when he 
becomes rich or powerful, he should help to save the world". This kind of life guideline, has been advocated by a lot of sages and heroes in the Chinese history.

The emperors of China always rely on good morality and cultural appeal rather than their mighty force to obtain the wide recognition of the surrounding tribes as well as the peaceful and harmonious environment. Therefore, when the Chinese feudal dynasty is prosperous and strong, it never sends expeditionary forces to invade or attack other nations, or to expend its territory, but sends messengers of civilization to travel all over the world to spread Chinese civilization and pervade the benevolence of the great kingdom. The traditional values of China-harmony and peacefulness, have even been inherited and carried forward by the contemporary Chinese government, the "Five Principles of Peaceful Coexistence" put forward by prime minister Zhou; the 'new security concept'; and the diplomacy of "an amicable, secure and prosperous neighborhood" all have inherited the traditional virtues.

\subsubsection{The United States-A Young Country}

The United States is one of the world's youngest countries, which only has a history of 200 years. The ancestors of Americans are the Puritans who have suffered religious persecution in Europe. In order to insist their religious belief, or be forced by the heavy pressure of life, those Puritans have to leave their homes and travel across the ocean to North America, the so-called New World. However, when they first arrive in the North American continent, what in front of them is not the blissful Garden of Eden in their mind, but the strange environment and the hard laboring. So, they have to depend on their own hands to create a new life in this strange new land. The first generation of American who come to the North America have experienced a lot of unexpected tribulations and sufferings. "Through constant battles against the aboriginal tribesmen of North America, they gradually build up a stable state and regime." (Hofstede, 1991) Under the baptism of tremendous sufferings and anguishes, the Americans have gradually formed the spirit of perseverance, individualism and pragmaticism. The strange unknown new environment cannot give them the sense of security. "As immigrants, they have to worry about their status and living all the time." (Liu \& Shen, 2005) Naturally, the whole nation has formed a sense of suffering consciousness as time goes by. In no time will they not worry that their homes be robbed by the indigenous people, and in no time will they not try their utmost to expand their land area. The Americans make themselves become powerful and mighty through everlasting fights against their enemies to enhance their security.

"The two hundred years' short history of the United States is a history of constant expansion of territory and ceaseless battles." (Luo, 2006) The early immigrants, continuously gain the lands from the indigenous people with money or force. Since the War of Independence in 1775, the Americans have not only bought some of the colonies in North America from France, Britain and other countries, but also occupied part of the Mexican territory. During the World War I and II, the United States makes big money by selling weapons to both 
sides, and by exploiting the beaten countries. Ever since, the United States has become the richest and most advanced nation in the world, and now, it is still the world's only super country, whose sphere of influence has extended to the whole world.

However, "with the increase of the comprehensive national strength of the United States, the whole nation's sense of crisis and insecurity, and the attempt to expand its Sphere of influence are also enlarging rather than diminishing." (Feng, 2002) They have been exporting the American concept of democracy and values to the whole world, and considering it as their responsibility to spread the most "perfect" democracy.

Being a young as well as the world's most developed nation, the America does not like being teased by other ancient nations that they have no sound and profound culture or tradition. In order to obtain higher international prestige and enlarge its sphere of influence in the world, the government of the United States has to inherit and spread expansionism.

\subsection{A Country of Natives vs. a Country of Immigrants}

\subsubsection{China-A Country of Natives}

The Chinese nation is the native of the vast area of Zhongyuan that has been living here for more than five thousand years. The ancient Chinese shares the same ancestors, values, legends, and so on. They all consider themselves as the descendants of the legendary Emperor Yan and Emperor Huang, the inheritor of Dragon.

"As natives of the vast inland area, the ancient Chinese regard themselves as the masters of the land, and believe that nobody can rob them of their Heaven-given lands. So, they cultivate and protect the land with their hearts." (Stavrianos, 1999) With favorable natural conditions and abundant resources provided by the land, the ancient Chinese have been living comfortably on self-sufficient agricultural life style. The fertile soil and the pleasing climate enable them to live a self-sufficient life just by farming. Thus, "in the long farming life, the Chinese has gradually developed the nature worship and the natural ideology of "nature and human come into one", which highlights the importance of harmony." (Cui, 2008) And Chinese people have learnt that we human beings should live in harmony with the earth, the nature, and also with each other.

Our ancestors, with unlimited imagination and romantic feelings, have created a lot of romantic and mysterious legends that happen on their motherland, such as the legends about the origin of the Chinese nation: the myth about "the Five Emperors", the legend about Fu Xi and $\mathrm{Nu}$ Wa, the myth on Pan-gu Creating the Heaven and the World, and the story about the King Houyi shooting the ten suns, etc. Based on their understanding of the nature and the cosmos, the imaginative ancient Chinese have also created the unique theory of Yin Yang to explain the mysterious and changeful natural phenomena.

Being the masters of Zhongyuan, a land with such advantaged nature, the 
ancient Chinese live a relatively richer and more comfortable life than the minorities. They need not worry about their living, thus have enough time and energy to extend their imagination unboundedly to create romantic and mysterious legends and myths.

All in all, being the natives of the great kingdom of China, the Chinese people feel rather safe and self-content, thus they live in harmony with each other. Such relatively comfortable life has helped them develop their romantic feelings.

\subsubsection{The United States-A Country of Immigrants}

The ancestors of Americans are Europeans. In the year 1607, the English Captain John Smith leads the first immigrants to travel across the sea to North America. Together, they have established the first English colony in this New World. Most of the immigrants are Puritans, who have suffered cruel religious persecution in Europe. In order to insist their religious belief and to maintain their life, those Puritans have to leave their homes and immigrate to North America, a place that is quite far away from the European continent.

As is well known, a completely new, strange, and unfamiliar environment will make people feel unsafe and trigger their inner fear and trepidation about the unknown challenge of life. "The first time when those Puritans step on the new land, they are bound to be surrounded by the sense of huge insecurity and uneasiness. The harsh and tough natural conditions, the variable climate and the constant harassment from the aboriginal Indians have compelled those immigrants to prepare to tackle various challenges at any time." (Kennedy, 1988)

Being immigrants, the Americans have to work hard and fight against the nature and the Indians constantly. Having long been in a state of confrontation with surrounding environment, the immigrants gradually feel a sense of suffering consciousness. The only way to reduce the sense of suffering is to make themselves stronger and mightier. "So, Americans will try every means to expand their land and enlarge their power." (Xia, 2008) For example, they have initiated innumerable battles against the Indians and occupied their lands. In order to exploit the vast waste land, they have launched the villainous Slave Trade.

Life is tough for the early American immigrants. The tough life forced them to become increasingly realistic and egocentric, and also excited their potential. "It is the immigrating life that has fostered the Americans faith to conquer the nature and change the world." (Gorden, 1964: p. 98)

\subsection{Influence of Different Religions}

\subsubsection{Influence of Confucian Ideology on Chinese}

"Traditional Chinese culture is a kind of inland culture built on the Confucian ideology." (Tang, 2001) And the core idea of Confucianism is "love and toleration", which means one should not only love himself, but also extend his love to all the creation. Confucius once said "One should expend the respect of the aged in his family to that of other families and the love of the young ones in his family to that of other families." Confucianism advocates simplicity, harmony, symmetry 
and the doctrine of the mean. It educates people not to do extreme things. "The doctrine of the mean respected by Chinese highlights the appropriate adjustment and compromise in interpersonal communication." (Yang, 2000) "Do not put the things on others which you do not want to be put on yourself" recorded in the Analects of Confucius tells everybody to put himself in others' shoes, so that we can better understand each other.

Influenced by the ancient nature worship and the natural ideology of "nature and human come into one"-which means man must live in harmony with nature, Confucianism highlights the harmonious and friendly relationship among we human beings and between human society and nature. The stress of harmony has engendered the highlight of collectivism among ancient Chinese. Confucius once said, if one conceals his ability that can help the common people and contribute to his country, but chooses to be a hermit to preserve his own moral integrity, then he is not a real hero. From what Confucius said, we could easily know that the Chinese has accepted the notion that "the country or collective always comes first, when compared with one's personal interest" since very old times.

\subsubsection{Influence of Christianity on Americans}

As a country of immigrants, the United States is a typical multi-ethnic and multi-cultural country with complex religious beliefs. But the Christianity is the one which has the biggest influence on Americans. It has been brought to North America by the European immigrants since the year 1607.

"Christians view that human beings are born equal, and have the same rights to pursue a better life." (Sun, 2004) They stress the role of the individual, and have a strong egocentric sense. Influenced by the Christianity, the Americans have developed the egoism ideology, which emphasizes that the sacred personal rights can not be infringed.

"Christians regard themselves as God's children, and believe that they have been chosen by God to spread its evangel." (Larsen \& Buss, 2002) Thus Christians take preaching as their primary responsibility. They take every chance to spread ideas in Bible to the unbelievers, and try their best to convert them to a God believer. The behavior of Preaching itself is a kind of mentality expansion to others' mind.

Believing be chosen by God, the Americans think that they have the world's best system and concept of value. They have the responsibility to spread the most "perfect" democracy to the world, in accordance with God's will.

\section{Conclusion}

The discussion on Chinese and American cultural differences reflected by Chinese dragon and American eagle, and the analysis of the reasons that lead to these differences have reached the conclusion that there are many cultural differences between these two countries. Generally speaking, Chinese culture is more romantic. It emphasizes the role of the collective, and highlights the harmonious 
and peaceful living environment. While, the American culture is more realistic, it emphasizes the role of individual. As a country of immigrants, there is a sense of suffering and crisis in American culture, and expansionism is also very important in American culture. From the analysis, we can see all the cultural characteristics of the two countries can be reflected respectively by dragon and eagle. Thus, it has been proved in the paper that dragon and eagle reflect cultural differences between China and America.

However, there are also two deficiencies in this paper. First, there is no consensus on the origin of the dragon and scholars still have disputes on it. This paper only takes one of those views-the dragon is not a real creature, but a supernatural thing endowed by ancient Chinese. So, the description may be biased. Second, since I have never been to the United States in person, all the narrations about USA are from relevant literature descriptions, so they are second hand materials. The authenticity of these materials needs to be proved.

\section{Project}

Guizhou provincial foreign students brand courses (2016JWP-4).

\section{Funding}

This study is supported by the master's research start-up fund of Zunyi Medical University.

\section{Conflicts of Interest}

The authors declare no conflicts of interest regarding the publication of this paper.

\section{References}

Cui, D. W. (2008). Influence of "Globalism" on Chinese Cultural Strategy. Journal of Suihua College, 28, 15-17. (In Chinese)

Feng, Z. H. (2002). Review on American Culture. Chengdu: Sichuan People’s Publishing House. (In Chinese)

Gorden, M. M. (1964). Assimilation in American Life-The Role of Race, Religion and National Origins. New York: Oxford University Press.

Gudykunst, W. B., \& Kim, Y. Y. (1997) Communicating with Strangers: An Approach to International Communication (3rd ed., p. 72). New York: McGraw-Hill.

Hofstede, G. (1991). Culture and Origination. New York: McGraw-Hill.

Hofstede, G. (2001). Culture's Consequences: Comparing Values, Behaviors, Institutions, and Organizations across Nations (2nd ed.). California: Sage Publications.

Kennedy, P. (1988). The Rise and Fall of the Great Powers. Beijing: Realistic Press.

Larsen, R., \& Buss, D. M. (2002). Personality Psychology: Domains of Knowledge about Human Nature. New York: McGraw-Hill.

Liu, X. D., \& Shen, X.J. (2005) “Expansionism” in American Diplomacy. Journal of Nanjing Institute of Political Science, 21, 48-50. (In Chinese)

Luo, W. Y. (2006). The Relationship between American Expansionism and Isolationism. 
Journal of Western China Normal University, No. 1, 109-112. (In Chinese)

Ren, L. L. (2010). Analysis of Cultural Differences between China and America. Journal of Hubei University of Economics, 7, 109-110. (In Chinese)

Song, X. Z. (2007). Comparison of Cultural Differences between China and the United States-The Influence of Religion and Philosophy on Cultural Differences between China and the United States. Forest School, No. Z1, 155-156. (In Chinese)

Stavrianos, L. S. (1999). A Global History (Volume 2). Shanghai: Shanghai Academy of Social Sciences Press.

Su, B. Q. (1982). New Exploration of the Origin of Chinese Civilization. Beijing: Sanlian Bookstore. (In Chinese)

Sun, Z. (2004). An Analysis of the Normative Position of American Realism. World Economy and Politics, No. 8, 31-36. (In Chinese)

Tang, Y. J. (2001). Chinese Confucian Culture. Beijing: Peking University Press. (In Chinese)

Wang, X. L. (2007). The Development of and the Differences Between Ancient and Modern Chinese Romantic Literature. Journal of Guangdong Ocean University, 27, 73-76. (In Chinese)

Xia, L. Y. (2008). An Analysis of Cultural Differences between China and America. Journal of Guizhou University of Technology, No. 5, 184-185. (In Chinese)

Yang, C. M. (2000). A Comprehensive Analysis on Confucian Culture. Jinan: Qi-Lu Bookstore. (In Chinese)

Zeng, D. C. (2001). Chinese Traditional Culture. Chengdu: Ba-Shu Bookstore. (In Chinese)

Zhang, H., \& Zhang, Y. Q. (2008). Formation and Development of Chinese Dragon Culture and Sino-foreign Cultural Communication. Journal of Hebei Normal University, 31, 157-160. (In Chinese) 